\title{
Thyroid disorders in antenatal women in a rural hospital in central India
}

\author{
Kalyani S. Mahajan ${ }^{1}$, Chella Hariharan ${ }^{1}$, Satish N. Mahajan ${ }^{2}$, Deepti S. Shrivastava ${ }^{1}$ \\ ${ }^{1}$ Department of Obstetrics \& Gynaecology, Jawaharlal Nehru Medical College, Sawangi-Meghe, Wardha, \\ Maharashtra, India \\ ${ }^{2}$ Department of Medicine, Jawaharlal Nehru Medical College, Sawangi-Meghe, Wardha, Maharashtra, India
}

Received: 20 October 2015

Accepted: 12 December 2015

\section{*Correspondence:}

Dr. Kalyani S. Mahajan,

E-mail: kalyanimahajandr@gmail.com

Copyright: (c) the author(s), publisher and licensee Medip Academy. This is an open-access article distributed under the terms of the Creative Commons Attribution Non-Commercial License, which permits unrestricted non-commercial use, distribution, and reproduction in any medium, provided the original work is properly cited.

\begin{abstract}
Background: Thyroid disorders are one of the most common endocrine disorders in pregnancy. Thyroid disorders are known to be associated with abnormal maternal and fetal outcomes and are often overlooked in pregnant women because of nonspecific symptoms and hypermetabolic state of pregnancy.

Methods: 514 women between 12 to 18 weeks of pregnancy from October 2013 to September 2015were recruited in the study. Serum thyroid-stimulating hormone (TSH) testing was done. Free T4 and free T3 were tested in subjects with a deranged TSH value. Subjects were followed up till delivery, and maternal and fetal complications arising out of thyroid dysfunction were studied.

Results: The occurrence of subclinical hypothyroidism was 9.54\%, overt hypothyroidism was $2.34 \%$ and hyperthyroidism was $0.58 \%$. When compared to subjects with euthyroidism, anemia and preterm delivery were the most significant maternal complications in subjects with hypothyroidism $(\mathrm{p}=0.0001$ and 0.0001 , respectively) whereas miscarriage, IUD/stillbirth, LBW and intrauterine growth restriction were significant fetal complications observed in subjects with hypothyroidism, with $\mathrm{p}<0.0001, \mathrm{p}=0.002,0.025,0.009$ respectively. NICU admissions were 2.58 times more in subjects with thyroid disorders as compared to euthyroid subjects.

Conclusions: The occurrence of thyroid disorders was high in our study with associated adverse maternal and fetal outcomes. Routine screening for thyroid dysfunction is recommended to prevent adverse fetal and maternal outcomes. Serum TSH is a sufficient and cost-effective screening tool.
\end{abstract}

Keywords: Thyroid dysfunction, Fetal outcome, Maternal outcome

\section{INTRODUCTION}

Thyroid physiology plays a major role in pregnancy and thyroid disorders constitute one of the most common endocrine disorders in pregnancy. ${ }^{1}$ Pregnancy is associated with significant and reversible changes in thyroid function. During pregnancy, there is an enhanced urinary loss of iodine owing to an increased glomerular filtration rate, leading to iodine deficiency and maternal goitre. ${ }^{2}$ There is an increase in thyroxine-binding globulin (TBG) because of elevated oestrogen and decrease in the level of thyroid-stimulating hormone (TSH) with an increase in human chorionic gonadotropin concentration. ${ }^{2}$ Placenta produces the enzyme deiodinase, which increases the peripheral metabolism of thyroid hormones and regulates the transplacental transport of thyroid hormone and iodide. ${ }^{2}$ In essence, pregnancy is a stress for the thyroid, resulting in hypothyroidism in women with limited thyroidal reserve or iodine deficiency.

The physiological changes of pregnancy can simulate thyroid disease. Symptoms of heat intolerance, sluggishness, fatigue, constipation and examination findings of tachycardia, edema, and wide pulse pressure 
are common to pregnancy and thyroid disease much in same way. ${ }^{2}$

The developing fetus synthesizes thyroid hormones only by the end of the first trimester and, hence, depends on the maternal thyroid hormone for organogenesis, general growth, and development of the central nervous system. Moreover, thyroid hormones are essential for the maintenance and successful completion of normal pregnancy. $^{2}$

Women with thyroid dysfunction both overt and subclinical are at increased risk of pregnancy-related complications such as threatened abortion, preeclampsia, preterm labor, placental abruption, and postpartum hemorrhage. Fetal complications include low birth weight babies, first trimester spontaneous abortions, preterm delivery, fetal or neonatal hyperthyroidism, intrauterine growth retardation, high rates of still birth and neonatal deaths, neonatal hyperbilirubinemia, higher incidence of neonatal hypothyroidism and increased perinatal mortality. ${ }^{1}$ It is now well established that not only overt, but subclinical thyroid dysfunction also has adverse effects on maternal and fetal outcome.

There are two main clinical forms of hypothyroidism. First is subclinical hypothyroidism, which is characterized by an elevated serum TSH with normal free thyroxine (FT4) and is observed in 3\%-5\% of women in pregnancy. Second is overt hypothyroidism, characterized by an elevated serum TSH and subnormal FT4 is observed in $0.3 \%-0.5 \%$ of women in pregnancy. ${ }^{2}$

Occurrence of hyperthyroidism is less during pregnancy with the prevalence being $0.1 \%-0.4 \%$. $^{3}$

Universal TSH screening is not yet a recommendation. But looking at the high percentage of abnormal TSH in pregnancies, universal screening should be considered as they are one of the easily treatable conditions.

India is known to have high incidence of thyroid dysfunction during pregnancy.

Shown by various studies the prevalence of thyroid disorders is as follows.

- Asian-Indian Pregnant Women -hypothyroidism $(4.8 \%)^{2}$

- Indian pregnant women - subclinical hypothyroidism in $6.47 \%$ and overt hypothyroidism in $4.58 \%{ }^{4}$

- North India - subclinical hypothyroidism $14.3 \% .^{5}$

- South Indian subjects- Subclinical hypothyroidism $2.8 \%{ }^{6}$

There is a dearth of studies showing the prevalence of overt and subclinical thyroid dysfunction in pregnant women and its effect on the maternal and fetal outcomes; moreover, data on the thyroid dysfunction during pregnancy has not been extensively studied in central
India/Vidarbha as well. Hence, our study is a sincere effort to throw some light in this direction.

\section{METHODS}

The Observational, prospective study was carried out in the Department of Obstetrics and Gynaecology, Acharya Vinoba Bhave Rural Hospital of Jawaharlal Nehru Medical College, Sawangi-Meghe, Wardha, Maharashtra, India during the period of 2 years from October 2013 to September 2015. The study was conducted after ethical clearance from the institutional ethical committee.

Total 514 Antenatal cases attending OPD between 12 to 18 weeks of pregnancy, including multiple gestations, were randomly selected and were followed till delivery. Subjects with known thyroid disorder were excluded from the study.

After a detailed history and examination, a screening for thyroid disorder was done with serum TSH assay. Those with abnormal TSH were subjected to FT4, FT3.

The reference range used in the study was based on the guidelines of the American Thyroid Association, 2011, for the diagnosis and management of thyroid disease during pregnancy and postpartum period. ${ }^{7}$ According to the guidelines, if trimester-specific ranges for $\mathrm{TSH}$ are not available in the laboratory, the following reference ranges are recommended; first trimester, $0.1-2.5 \mu \mathrm{IU} / \mathrm{mL}$; second trimester, $0.2-3.0 \mu \mathrm{IU} / \mathrm{mL}$ and third trimester, $0.3-3.0 \mu \mathrm{IU} / \mathrm{mL}$. TSH was assayed by VIDAS based on based on the ELFA (Enzyme Linked Fluorescent Assay) technique.

Subjects were followed up and pregnancy outcomes were noted in terms of pre-eclampsia, anaemia, preterm delivery, abruptio placenta, oligo/polyhydramnios, miscarriage, IUD/stillbirth, IUGR, LBW, NICU admissions, mode of delivery.

\section{Biostatic analysis}

- Statistical analysis was done using descriptive and inferential statistics. Tests used for analysis were Chi Square Test, Z Test and odds Ratio.

- The results were analysed by using software SPSS 17.0 version and results were tested at 5\% level of significance and Graph pad prism 5.0 version.

- P value of $<0.05$ was considered as significant.

\section{Definitions}

- Pre-eclampsia was defined as persistently elevated blood pressure (systolic $\geq 140 \mathrm{mmHg}$ and diastolic $\geq 90 \mathrm{mmHg}$ ) on two or more occasions with proteinuria, after $20^{\text {th }}$ week with previously normotensive and nonproteinuric women. 
- Anaemia was defined as maternal hemoglobin contraction in peripheral blood $<11 \mathrm{gm} / \mathrm{dl}$.

- Abruptio placenta was defined as a form of antepartum hemorrhage where the bleeding occurs due to premature separation of normally situated placenta.

- $\quad$ Preterm delivery was defined as delivery before 37 completed weeks of gestation.

- Oligohydramnios was defined as condition where the liquor amnii if deficient in amount to the extent of less than $200 \mathrm{ml}$ at term or sonographically amniotic fluid index is $<5 \mathrm{~cm}$.

- Polyhydramnios was defined as a state where liquor amnii exceeds $2000 \mathrm{ml}$ or sonographically when amniotic fluid index is $24 \mathrm{~cm}$.

- Miscarriage was defined as spontaneous expulsion of an embryo or fetus weighing $500 \mathrm{gm}$ or less when is not capable of independent survival.

- IUD was defined as intrauterine fetal demise after the period of viability.

- Stillbirth was defined as death after $28^{\text {th }}$ completed week during labour when the baby does not show any sign of life after delivery.

- IUGR was defined as birth weight of baby less than $10^{\text {th }}$ percentile of average for the gestational age.
- Low birth weight was defined as infant with birth weight of less than $2500 \mathrm{gm}$ irrespective of gestational age.

\section{RESULTS}

Out of 514 subjects, 64 had deranged thyroid function, making the prevalence of thyroid dysfunction.

$12.45 \%$. Prevalence of overt hypothyroidism was $2.34 \%$ and $9.54 \%$ had subclinical hypothyroidism. The prevalence of hyperthyroidism was $0.58 \%$ in our study.

\section{Baseline characteristics study population}

Maternal demographic characters are shown in Table 1. Maternal age was high in the subjects with thyroid disorders. No significant statistical difference was seen with respect to parity in different groups.

Mean TSH level in euthyroid subjects was $1.53 \pm 0.58$, in subclinical hypothyroid subjects it was $4.95 \pm 3.51$, in overt hypothyroid subjects it was $6.13 \pm 2.31$ and in hyperthyroid subjects it was $0.06 \pm 0.05$.

Table 1: Baseline characteristics study population.

\begin{tabular}{|lllll|}
\hline Thyroid status & $\mathrm{n}$ & $\%$ & Mean TSH levels (mIU/L) & Mean age (years) \\
\hline Euthyroid & 450 & 87.54 & $1.53 \pm 0.58$ & $24.42 \pm 3.49$ \\
\hline Subclinical hypothyroidism & 49 & 9.54 & $4.95 \pm 3.51$ & $26.28 \pm 4.40$ \\
\hline Overt Hypothyroidism & 12 & 2.34 & $6.13 \pm 2.31$ & \\
\hline Hyperthyroidism & 3 & 0.58 & $0.06 \pm 0.05$ & \\
\hline Total & 514 & 100.00 & $1.96 \pm 1.73$ & \\
\hline F-value & $155.44, \mathrm{p}=0.0001, \mathrm{~S}, \mathrm{p}<0.05$ & \\
\hline
\end{tabular}

This table shows that $48.99 \%$ of euthyroid subjects and $28.57 \%$ of subjects with thyroid dysfunction had previous normal obstetric outcome, $41.30 \%$ euthyroid subjects and $40 \%$ of subjects with thyroid dysfunction had miscarriage in previous pregnancy, $4.05 \%$ euthyroid subjects and $14.29 \%$ of subjects with thyroid dysfunction had IUD/still births, $3.24 \%$ of euthyroid subjects and $8.57 \%$ of subjects with thyroid dysfunction had neonatal mortality and $2.43 \%$ of euthyroid subjects and $8.57 \%$ of subjects with thyroid dysfunction had both Miscarriage and IUD/still birth in previous pregnancy. By using chi square test statistically significant difference was found between two groups $\left(\aleph^{2}\right.$-value $=14.66, \quad \mathrm{p}=0.005$, Significant) (Table 2).

Table 3 shows that $6.38 \%$ of euthyroid subjects, $10.42 \%$ of subjects with subclinical hypothyroidism and $25 \%$ of subjects with overt hypothyroidism had miscarriage $(\mathrm{p}<0.0001, \mathrm{~S})$.
$1.16 \%$ of euthyroid subjects, $2.08 \%$ of subjects with subclinical hypothyroidism and $8.33 \%$ of subjects with overt hypothyroidism had IUD/still births $(\mathrm{p}=0.002, \mathrm{~S})$.

$3.77 \%$ of euthyroid subjects, each $8.33 \%$ of subjects with subclinical hypothyroidism and overt hypothyroidism had LBW ( $\mathrm{p}=0.025, \mathrm{~S})$ and $5.22 \%$ in euthyroid subjects and $6.25 \%$ of subjects with subclinical hypothyroidism had IUGR $(\mathrm{p}=0.009, \mathrm{~S})$.

By using chi square test statistically significant difference was found between fetal outcome and thyroid status of subjects $\quad\left(\kappa^{2}\right.$-value $=175.80, \quad \mathrm{p}<0.0001, \quad$ Significant, $\mathrm{p}<0.05)$.

Also no significant association was found between mode of delivery and thyroid status of the subjects $\left(\kappa^{2}\right.$ value $=2.01, \mathrm{p}$ value $\left.=0.36\right)$. 
Table 2: Correlation of thyroid status with previous obstetric outcome.

\begin{tabular}{|lllllll|}
\hline \multirow{2}{*}{ Previous obstetric outcome } & \multicolumn{3}{l}{ Euthyroid Subjects } & Subjects with thyroid dysfunction & Total \\
& $\mathrm{N}$ & $\%$ & $\mathrm{~N}$ & $\%$ & $\mathrm{n}$ & $\%$ \\
\hline Normal & 121 & 48.99 & 10 & 28.57 & 131 & 46.45 \\
\hline Miscarriage & 102 & 41.30 & 14 & 40.00 & 116 & 41.13 \\
\hline IUD/Still births & 10 & 4.05 & 5 & 14.29 & 15 & 5.32 \\
\hline Neonatal Mortality & 8 & 3.24 & 3 & 8.57 & 11 & 3.90 \\
\hline Miscarriage +IUD /Still births & 6 & 2.43 & 3 & 8.57 & 9 & 3.19 \\
\hline Total & 247 & 100 & 35 & 100 & 282 & 100 \\
\hline $\boldsymbol{N}^{2}$-value & $14.66, \mathrm{p}=0.005$, Significant & & & & \\
\hline
\end{tabular}

Table 3: Correlation of thyroid status with fetal outcome.

\begin{tabular}{|c|c|c|c|c|c|c|c|c|c|c|c|}
\hline \multirow{2}{*}{$\begin{array}{l}\text { Fetal } \\
\text { outcome } \\
\mathbf{N}=\mathbf{4 0 8}\end{array}$} & \multicolumn{2}{|c|}{ Euthyroid } & \multicolumn{2}{|c|}{$\begin{array}{l}\text { Subclinical } \\
\text { hypothyroidism }\end{array}$} & \multicolumn{2}{|c|}{$\begin{array}{l}\text { Overt } \\
\text { hypothyroidism }\end{array}$} & \multicolumn{2}{|c|}{ Hyperthyroidism } & \multicolumn{2}{|c|}{ Total } & \multirow[t]{2}{*}{ p-value } \\
\hline & $\mathrm{N}$ & $\%$ & $\mathrm{n}$ & $\%$ & $\mathrm{n}$ & $\%$ & $\mathrm{n}$ & $\%$ & $\mathrm{n}$ & $\%$ & \\
\hline Normal & 288 & 83.48 & 35 & 72.92 & 7 & 58.33 & 1 & 33.33 & 331 & 81.13 & $\mathrm{p}<0.0001, \mathrm{~S}$ \\
\hline Miscarriage & 22 & 6.38 & 5 & 10.42 & 3 & 25.00 & 2 & 66.67 & 32 & 7.84 & $\mathrm{p}<0.0001, \mathrm{~S}$ \\
\hline $\begin{array}{l}\text { IUD/Still } \\
\text { Birth }\end{array}$ & 4 & 1.16 & 1 & 2.08 & 1 & 8.33 & 0 & 0.00 & 6 & 1.47 & $0.002, \mathrm{~S}$ \\
\hline LBW & 13 & 3.77 & 4 & 8.33 & 1 & 8.33 & 0 & 0.00 & 18 & 4.41 & $0.025, \mathrm{~S}$ \\
\hline IUGR & 18 & 5.22 & 3 & 6.25 & 0 & 0.00 & 0 & 0.00 & 21 & 5.15 & $0.009, \mathrm{~S}$ \\
\hline Total & 345 & 100 & 48 & 100 & 12 & 100 & 3 & 100 & 408 & 100 & \\
\hline$\aleph^{2}$-value & \multicolumn{11}{|c|}{$175.80, \mathrm{p}<0.0001$, Significant, $\mathrm{p}<0.05$} \\
\hline
\end{tabular}

Table 4 shows that babies of $21.32 \%$ of euthyroid subjects, $40.48 \%$ of subjects with subclinical hypothyroidism and $50 \%$ of subjects with overt hypothyroidism needed NICU admissions $(\mathrm{p}<0.0001)$. Statistically significant association was found between NICU admission of babies and thyroid status of the subjects $\left(\aleph^{2}\right.$-value $=74.68, \mathrm{p}<0.0001$, Significant, $\left.\mathrm{p}<0.05\right)$.
Table 5 shows that $10.52 \%$ out of 343 euthyroid subjects, $13.95 \%$ out of 43 subjects with subclinical hypothyroidism and $33.33 \%$ out of 9 subjects with overt hypothyroidism had preterm deliveries ( $\mathrm{p}=0.0001, \mathrm{~S})$. $18.26 \%$ of euthyroid subjects, $23.25 \%$ of subjects with subclinical hypothyroidism and $55.99 \%$ of subjects with overt hypothyroidism had anemia $(\mathrm{p}=0.0001, \mathrm{~S})$.

Table 4: Correlation of NICU admission amongst different study groups.

\begin{tabular}{|c|c|c|c|c|c|c|c|c|c|c|c|}
\hline \multirow{2}{*}{$\begin{array}{l}\text { NICU } \\
\text { admission }\end{array}$} & \multicolumn{2}{|c|}{ Euthyroid } & \multicolumn{2}{|c|}{$\begin{array}{l}\text { Subclinical } \\
\text { hypothyroidism }\end{array}$} & \multicolumn{2}{|c|}{$\begin{array}{l}\text { Overt } \\
\text { hypothyroidism }\end{array}$} & \multicolumn{2}{|c|}{ hyperthyroidism } & \multicolumn{2}{|c|}{ Total } & \multirow[t]{2}{*}{ p-value } \\
\hline & $\mathrm{N}$ & $\%$ & $\mathrm{~N}$ & $\%$ & $\mathrm{n}$ & $\%$ & $\mathrm{n}$ & $\%$ & $\mathrm{n}$ & $\%$ & \\
\hline No & 251 & 78.68 & 25 & 59.52 & 4 & 50 & 1 & 100 & 281 & 75.95 & $\mathrm{p}<0.0001, \mathrm{~S}$ \\
\hline Yes & 68 & 21.32 & 17 & 40.48 & 4 & 50 & 0 & 0 & 89 & 24.05 & $\mathrm{p}<0.0001, \mathrm{~S}$ \\
\hline Total & 319 & 100 & 42 & 100 & 8 & 100 & 1 & 100 & 370 & 100 & \\
\hline$\aleph^{2}$-value & \multicolumn{11}{|c|}{$74.68, \mathrm{p}<0.0001$, Significant, $\mathrm{p}<0.05$} \\
\hline
\end{tabular}

Table 5: Correlation of thyroid status with adverse maternal outcome.

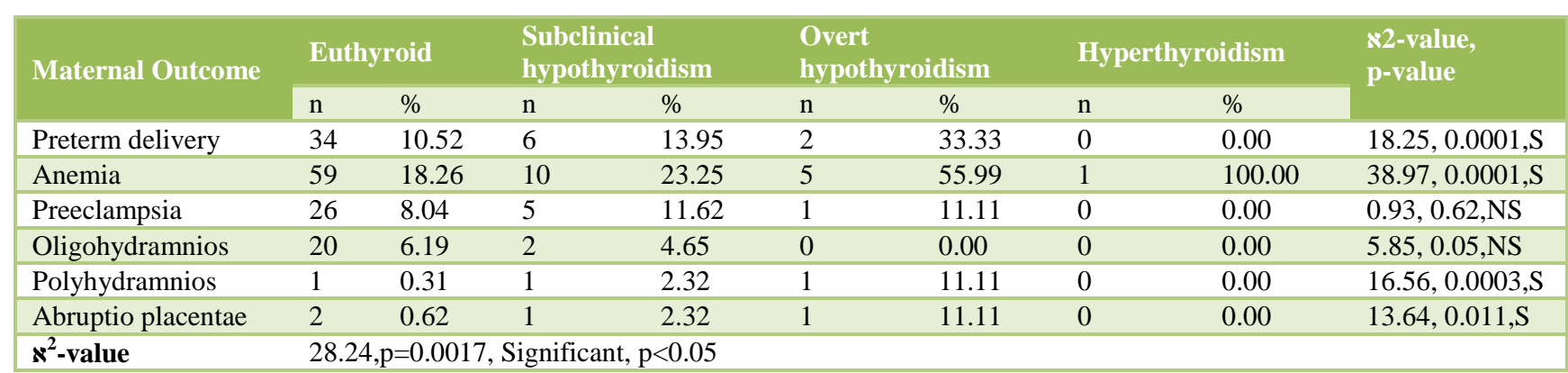


$8.04 \%$ of euthyroid subjects, $11.62 \%$ of subjects with subclinical hypothyroidism and $11.11 \%$ of subjects with overt hypothyroidism had Preeclampsia ( $\mathrm{p}=0.62$, NS).

$6.19 \%$ of euthyroid subjects, $4.65 \%$ of subjects with subclinical hypothyroidism had oligohydramnios ( $\mathrm{p}=0.05, \mathrm{NS}$ ). $0.31 \%$ of euthyroid subjects and $2.32 \%$ and $11.11 \%$ of subjects with subclinical hypothyroidism and overt hypothyroidism had polyhydramnios $(\mathrm{p}=0.0003, \mathrm{~S})$.

$0.62 \%$ of euthyroid subjects, $2.32 \%$ of subjects with subclinical hypothyroidism and $11.11 \%$ of subjects with overt hypothyroidism had Abruptio placentae ( $\mathrm{p}=0.011$, S).

Subjects with Hyperthyroidism were not included at the time of statistical analysis as there were only $3(0.58 \%)$ cases.

\section{DISCUSSION}

Thyroid dysfunction is common, treatable, and to some extent preventable condition which produce morbidity and pose special risks for pregnancy and the developing fetus. Screening for thyroid dysfunction in a woman who is pregnant or wants to be pregnant is important because thyroid hormone status is directly related to fetal brain development.

Occurrence was high in our study with $2.34 \%$ of overt and $9.54 \%$ of subclinical hypothyroid subjects, thus necessitating the need for screening for thyroid dysfunction.

In our study, it was noted that women with thyroid disorders had higher mean maternal age as compared to euthyroid women. The increase in prevalence of hypothyroidism in the older age group is due to current trend of older women becoming pregnant.

A study done by Ajmani Sangita Nangia et al, in 2013 reported the incidence of subclinical and overt hypothyroidism in India as $9 \%$ and $3 \%$, respectively. ${ }^{1}$ However, the prevalence of subclinical hypothyroidism in northern and southern parts of India was reported as $13.5 \%$ and $16.12 \%$, respectively, in other studies.

In our study, anemia and preterm delivery were the most common maternal complications in subjects with hypothyroidism. Similar results were found by Chauhan Rooplekha et al in 2015. ${ }^{9}$ In our study, no significant association was found between mode of delivery and thyroid status of the subjects. In addition, hypothyroidism increased the risk of NICU admissions, which is in agreement with the study done by Nidhi Chauhan et al in 2014. ${ }^{10}$
In our study, the occurrence of miscarriage $(p<0.0001, S)$ and fetal death $(\mathrm{p}<0.0002, \mathrm{~S})$ were significantly higher in the pregnant women with hypothyroidism. Also, the pregnant women with subclinical and overt hypothyroidism had a significant increase in the incidence of intrauterine growth retardation $(\mathrm{p}=0.009, \mathrm{~S})$ and low birth weight $(\mathrm{p}=0.025, \mathrm{~S})$. Abnormal fetal outcome was 2.35 times more common in subjects with thyroid disorders as compared to euthyroid subjects $($ Odds ratio $=2.35)$.

Vimal Nambiar et al in their study found that $7.35 \%$ of euthyroid subjects, $13.33 \%$ of subjects with thyroid disorders had miscarriage, while $1.47 \%$ of euthyroid subjects, $2.85 \%$ subjects with thyroid disorders had still births. ${ }^{3}$ Similarly; Ajmani Sangita Nangia et al in their study reported a higher incidence of IUGR and LBW in pregnancies complicated by maternal hypothyroidism. ${ }^{1}$

Although hyperthyroidism in pregnancy is uncommon, its effects on both mother and child are critical. In our study, no significant conclusion could be drawn as only $0.58 \%$ subjects had hyperthyroidism.

\section{CONCLUSION}

The occurrence of thyroid disorders was high in our study with associated adverse maternal and fetal outcomes. Routine screening for thyroid dysfunction is recommended to prevent adverse fetal and maternal outcomes. Serum TSH is a sufficient and cost-effective screening tool.

\section{Funding: No funding sources}

Conflict of interest: None declared

Ethical approval: The study was approved by the Institutional Ethics Committee

\section{REFERENCES}

1. Nangia AS, Deepa A. Prevalence of Overt and Subclinical Thyroid Dysfunction among Pregnant Women and Its Effect on Maternal and Fetal Outcome. The Journal of Obstetrics and Gynecology of India. 2014;64(2):105-10.

2. Singh A, Reddy MJ. Prevalence of thyroid dysfunction in pregnancy and its implications. Int $\mathrm{J}$ Med Sci Public Health. 2015;4:1247-50.

3. Nambiar V, Jagtap VS, Sarathi V, Lila AR, Kamalanathan S, Bandgar TR et al. Prevalence and impact of thyroid disorders on maternal outcome in Asian-Indian pregnant women. J Thyroid Res. 2011;2011:429097.

4. Sahu MT, Das V, Mittal S, Agarwal A, Sahu M. Overt and subclinical thyroid dysfunction among Indian pregnant women and its effect on maternal and fetal outcome. Arch Gynecol Obstet. 2010;281:215-20. 
5. Dhanwal DK, Prasad S, Agarwal AK, Dixit V, Banerjee AK. Indian $\mathrm{J}$ Endocrinol Metab. 2013;17(2):281-4.

6. Gayathri R, Lavanya S, Raghavan K. Subclinical hypothyroidism and autoimmune thyroiditis in pregnancy - a study in South Indian subjects. J Assoc Physicians India. 2009;57:691-3.

7. Stagnaro-Green A. Recognizing, understanding, and treating postpartum thyroiditis. Endocrinology Metabolism Clinics of North America. 2000;29 (2):417-30.

8. Murty NVR, Uma B, Rao JM, Sampurna K, Vasantha K, Vijayalakshmi G. High prevalence of subclinical hypothyroidism in pregnant women in South India. Int J Reprod Contracept Obstet Gynecol. 2015;4:453-6.
9. Rooplekha C, Bharti S, Shama K. Prevalence Of Hypothyroidism Among Pregnant Women In Mahakaushal Area And Its Impact On Maternal And Fetal Outcome. International Journal Of Medical \& Applied Sciences . 2015;4(Suppl 1):140-7.

10. Chauhan N, Nautiyal R. To study the profile of thyroid function in pregnancy and its correlation with the maternal \& fetal outcome. International Journal of Biological \& Medical Research. 2014;5(4):45658 .

Cite this article as: Mahajan KS, Hariharan C, Mahajan SN, Shrivastava DS. Thyroid disorders in antenatal women in a rural hospital in central India. Int J Reprod Contracept Obstet Gynecol 2016;5:62-7. 